\title{
La crisis nuclear de Corea del Norte: Sky News o Fox News
}

\section{Pablo Rodríguez ${ }^{1}$ Dimitrina Jivkova Semova²}

Recibido: 2013-11-09

Envío a pares: 2013-11-12
Aprobado por pares: 2014-02-05

Aceptado: 2014-02-20

DOI: $10.5294 /$ pacla.2014.17.3.12

Para citar este artículo / To reference this article / Para citar este artigo

Semova-Jivkova, D. \& Rodríguez, P. Septiembre de 2014. La crisis nuclear de Corea del Norte: Sky News o Fox News. Palabra Clave 17 (3), 854-874. DOI: 10.5294/pacla.2014.17.3.12

\section{Resumen}

En este artículo analizamos, desde la teoría del framing, la información ofrecida por los dos canales de noticias 24 horas del grupo News Corporation, Sky News y Fox News, con relación a la crisis nuclear de Corea del Norte en el periodo 9 -23 de abril de 2013. Nos centramos en aspectos como la "foxificación", la presencia de expertos militares en los bloques de noticias y los encuadres informativos. En el caso de Sky News, la información se ofrece desde el prisma de los sucesos a nivel nacional debido al tiempo dedicado a la polémica con el documental del programa "Panorama" de la BBC. El tratamiento de la crisis nuclear en Fox News se traduce en constantes críticas a las políticas militares llevadas a cabo por Corea, la exaltación patriótica de los Estados Unidos poniendo el acento sobre el sistema defensivo y todo ello rodeado de una crítica feroz a la Administración Obama por no promover una intervención militar en el conflicto. 


\section{Palabras clave}

Crisis nuclear, discurso, framing, Sky News, Fox News (Fuente: Tesauro de la Unesco).

\section{The Nuclear Crisis in North Korea: Sky News or Fox News}

\section{Abstract}

The information provided by News Corporation's two 24-hour news channels: Sky News and Fox News, concerning the North Korean nuclear crisis during April 9 -23, 2013 is examined in this paper from the standpoint of the framing theory. The authors focus on aspects such as "Foxificación", the presence of military experts on news programs, and the diversity of frameworks for the news. In the case of Sky News, information is made available through the prism of national events, given the time devoted to the controversy with the BBC's "Panorama" program. Treatment of the nuclear crisis on Fox News translates into constant criticism of North Korea's military policy and patriotic exaltation of the United States, with emphasis on the defense system, all cloaked in fierce criticism of the Obama Administration for not promoting military intervention in the conflict.

\section{Keywords}

nuclear crisis, discourse, framing, sky News, Fox News (Source: UNESCO Thesaurus). 


\section{A crise nuclear da Coreia do Norte: Sky News ou Fox News}

\section{Resumo}

Neste artigo, analisamos, a partir da teoria do framing, a informação oferecida pelos dois canais de notícias 24 horas do grupo News Corporation, Sky News e Fox News sobre a crise nuclear da Coreia do Norte no período de 9 a 23 de abril de 2013. Centrou-se em aspectos como a "foxificação", a presença de especialistas militares nos blocos de notícias e no quadros informativos. No caso da Sky News, a informação foi oferecida a partir do prisma dos acontecimentos no âmbito nacional devido ao tempo dedicado à polêmica com o documentário do programa "Panorama", da BBC. O tratamento da crise nuclear na Fox News se traduz e constantes críticas às políticas militares realizadas pela Coreia, a exaltação patriótica dos Estados Unidos que enfatizou o sistema defensivo e tudo isso rodeado de uma crítica feroz à Administração Obama por não promover uma intervenção no conflito.

\section{Palavras-chave}

Crise nuclear, discurso, framing, Sky News, Fox News (Fonte: Tesauro da Unesco). 


\section{Introducción}

En la década de los sesenta, el déficit en el mercado de noticias de actualidad en los EE. UU. alcanzó niveles muy preocupantes, provocando que la Comisión Federal de Comunicaciones (FCC) adoptase una línea más intervencionista y obligando a los networks a aumentar las inversiones en este ámbito, siempre de conformidad con las normas de imparcialidad de la fairness doctrine. No obstante, desde la década de los ochenta, la desregulación empezó a ganar terreno y las prácticas y convenciones de programación de noticias de televisión ya no estuvieron sujetas a los mismos requisitos reglamentarios anteriormente vigentes. (Cushion, 2011; Freedman, 2008; McChesney, 2000, 2008; Cushion, Lewis, Neil Ramsay, 2012, p. 834).

Actualmente, las cadenas audiovisuales británicas operan en un sistema de regulación tripartita (Cushion, 2011). La mayoría de los nuevos canales dentro de esta estructura se rige por un marco conocido como light touch, con los canales comerciales 'antiguos' aún atados a algunos compromisos de servicio público y la $\mathrm{BBC}$ como el único organismo de radiodifusión con una misión de servicio público claramente definida. A partir de 2011, los canales comerciales en el Reino Unido están regulados por la Oficina de Comunicaciones (Ofcom, establecida en 2003) mientras que la BBC está regulada por el BBC Trust, creado en 2007 (Semova, 2012). ${ }^{3}$

En la práctica, los canales comerciales -ITV, Sky, Channel 4 y Channel 5- tienen diferentes niveles de responsabilidad con relación a la emisión de noticias y temas de actualidad. Sky, por ejemplo, tiene que cumplir con las leyes asegurando la imparcialidad del mismo modo que todas las cadenas en el Reino Unido, aunque no está legalmente obligada a proporcionar noticias o programas de actualidad. En 2011, cuando se hizo evidente la intención de Rupert Murdoch de comprar todas las acciones de BSkyB, se sugirió que Sky News podría ser vendida o incluso cerrada para no interferir en el acuerdo. ITV, Channel 4 y Channel 5, en cambio, operan bajo licencias de radiodifusión de servicio público donde el suministro de noti-

3 En el caso del Public Value Test, mecanismo que mide el impacto de la nueva oferta de la radiotelevisión pública, ambos organismos establecen una comisión conjunta de trabajo. 
cias y programas de actualidad es un requisito imprescindible. Uno de los debates hoy en día tiene que ver con el papel de ITV, uno de los principales canales comerciales en el Reino Unido y el que mayor grado de responsabilidad de servicio público ostenta debido a que se está considerando la opción de retirar la imposición de proporcionar noticias regionales a partir de 2014, cuando se le renueva la licencia (Cushion, Lewis, Neil Ramsay, 2012, p. 835).

En este artículo vamos a analizar, desde la teoría del framing, la vigencia de algunos puntos problemáticos detectados anteriormente por expertos en el campo como Lewis $(2009,2012)$ y Sirota $(2004)$ con relación a la información ofrecida por los dos canales de noticias 24 horas del grupo News Corporation, Sky News y Fox News. ${ }^{4}$ En este caso, nos centraremos en la cobertura mediática de la crisis nuclear de Corea del Norte en el periodo del 9 al 23 de abril de 2013.

En 2013, apareció con total fuerza en el espacio público la noticia sobre los ensayos nucleares de Corea del Norte, acompañados esta vez por amenazas de ataque a sus vecinos del sur y a Estados Unidos. El 12 de febrero, el país realizó la mayor prueba nuclear de su historia, provocando un seísmo de 5,0 en la escala de Richter. Después de las críticas y advertencias a nivel mundial, el 10 de marzo Corea del Norte eliminó todos los pactos vigentes de no agresión con Corea del Sur y puso sobre la mesa un posible ataque nuclear contra los Estados Unidos de América.

Las cuestiones centrales de la investigación a las que buscaremos una respuesta son las siguientes:

CI 1: Si bien hay algunas señales de 'Foxificación' en el caso de Sky News, las normas de servicio público sobre la radiodifusión en el Reino Unido y la presencia de la BBC actúan como contrafuerza en el proceso.

4 Grupo empresarial del sector de la comunicación creado por el magnate australiano Rupert Murdoch en 1980. Cuenta con importantes cabeceras de prensa escrita, revistas, radios y canales de televisiones entre las que destacan The New York Post, Fox, Sky, The Sun y Vogue. Sky News es un canal de televisión británico de noticias perteneciente al grupo News Corporation puesto en marcha en 1989. Fox News es que canal informativo que empezó a emitir en 1996. 
CI 2: Trasladándonos a la situación de conflicto global, analizaremos si sigue existiendo una dependencia significativa en Fox News de los expertos militares para interpretar temas de la política exterior de los Estados Unidos.

\section{Metodología}

El discurso siempre está vinculado a otros discursos producidos con anterioridad, simultáneamente o con posterioridad. Para una mejor comprensión debemos tener en cuenta su utilización en situaciones específicas, comprender las convenciones y reglas subyacentes, reconocer su inmersión en una ideología concreta y en la cultura y saber también a qué elementos del pasado se remite (Fairclough, 1995, 2002 y Wodak, 2005).

Para el análisis del discurso en este caso recurrimos a los planteamientos desarrollados desde la teoría del framing. Las diferentes vertientes sociológicas, como las impulsadas por la Escuela de Chicago o la fenomenología y la etnometodología, hacen posible la implantación del framing como concepto explicativo de las ciencias sociales. La sociología interpretativa estudia las significaciones de la realidad para cada individuo a través de un proceso interpretativo en el que cobra un papel fundamental la interacción y que tiene como objeto la definición de las situaciones cotidianas, por lo cual la teoría del framing se presenta como una herramienta esencial en los procesos de interpretación de significados.

Bateson (1993) define el frame como el marco de la realidad que hace que la gente se detenga en unos aspectos y desestime otros. Se trata de un proceso que sucede a tres niveles: referencial, metalingüístico y metacomunicativo. Goffman (2006) define marco (contexto de la realidad) y esquema (estructura mental) como términos que explican y sirven al mismo tiempo para referirse a la definición de la situación. El sociólogo canadiense introduce también el concepto de keying como una explicación de la transcripción de marcos que permite llegar a dar sentido a los hechos con nuevas interpretaciones.

Según Tuchman (1978), el frame crea distintas visiones de la realidad y por tanto fundamenta la pluralidad. Los periodistas son quienes or- 
denan la información para crear noticias y el proceso informativo se define como el método de recogida, selección y difusión de información vinculado a la organización en que se trabaja. La reflexividad y la indexividad, como componentes de la transformación de los sucesos en acontecimientos informativos, son dos elementos fundamentales dentro de esta teoría.

La teoría del framing ha desarrollado a lo largo de los años distintos enfoques y distintos métodos de análisis, como el análisis de contenido (Entman, 1991, 1993; Good, 2008; Zhou y Moy, 2007); el planteamiento denominado media package (Gamson y Modigliani, 1989), basado en palabras clave, lenguaje común, metáforas, frases clave, etc. (Pan y Kosicki, 1993), o en fotografías y material ilustrativo (Tankard, 200), y, por último, los métodos centrados en las funciones. Con los años se han introducido nuevos planteamientos: Tankard (2001) define el framing como la selección de la información, ya que los distintos frames se encuentran en los títulos, subtítulos, antetítulos, fotografías; Entman (1993) considera el frame como la selección de la realidad a través de una imagen que el propio periodista crea sobre lo que sucede en el mundo para hacer más notable la realidad ante su audiencia; Resse (2001) define el concepto como una estructura de conocimiento sujeto a determinados intereses, lo que significa que las relaciones de poder explican los frames.

El presente trabajo sigue el ejemplo de otros autores (Semetko y Valkenburg, 2000; De Vreese et al., 2001; Schuck y De Vreese, 2006) que apuestan por el método deductivo, que consiste en predefinir ciertos frames como categorías de análisis del contenido y, recurriendo a múltiples indicadores, detectar la presencia o ausencia de los mismos. Este método ha sido empleado junto con el enfoque hermenéutico, que trata de identificar los frames proporcionando una interpretación de los textos mediáticos basada en la conexión con elementos culturales más amplios. Arraigado en el paradigma cualitativo, este planteamiento se basa en pequeñas muestras que reflejan el discurso de un tema o un evento (Matthes y Kohring, 2008).

Señalizar los índices y elaborar los indicadores es un momento clave, ya que "se considera a los textos como una manifestación portadora de 
índices que el análisis va a hacer hablar" (Bardin, 2002). El índice que hemos elegido en este caso es la mención explícita de un tema con su correspondiente indicador: la frecuencia. El proceso de codificación ha sido llevado a cabo en tres pasos: 1) descomposición, consistente en la elección de las unidades, 2) enumeración y 3 ) clasificación, previa elección de categorías. Uno de los pasos más importantes supone elegir la unidad de registro, que en nuestro caso ha sido el tema, es decir, la descripción completa (inicio, desarrollo, final) de cualquier acontecimiento o hecho. ${ }^{5}$ Realizar un análisis temático consiste en localizar los 'núcleos de sentido' que componen la comunicación y cuya presencia o frecuencia de aparición tienen importancia para el objetivo analítico elegido. La clasificación ha sido llevada a cabo recurriendo a las categorías desarrolladas por Lasswell (1965, pp. 237-239) para el análisis de contenido: símbolos de la política doméstica, personas e instituciones relacionadas con el objeto de estudio, los símbolos de la moral, símbolos para la acción. A efectos del cómputo, han sido tomados en cuenta únicamente los bloques de noticias emitidos en directo en el periodo del 9 al 23 de abril de 2013, excluyendo las emisiones repetidas on record. Después de la descripción de la distribución temporal de las unidades, nos hemos centrado en los aspectos cualitativos de la información con el fin de hacer un análisis del discurso básico que, por su parte, nos conduce a los marcos interpretativos

\section{Análisis de los resultados}

En primer lugar, nos centraremos en el total de tiempo que dedican los dos canales de televisión a la temática de la crisis nuclear en Corea del Norte en el periodo del 9 al 23 de abril de 2013.

De los resultados obtenidos, queda claro que la cadena Fox News dedica más de 12500 segundos de emisión al tema, lo que supone aproximadamente tres horas y media. Al mismo tiempo, Sky News dedica un total de aproximadamente 1800 segundos, que se traducen en unos $30 \mathrm{mi}$ nutos de emisión total. En el caso de Sky News, tal y como nos muestra

5 Berelson (1971) define el tema como "una afirmación sobre un sujeto. Es decir, una frase, o una frase compuesta, habitualmente un resumen o una frase condensada, tras la cual puede resultar afectado un vasto conjunto de formulaciones singulares". 
el gráfico 2, aparece información sobre la crisis nuclear los días 9, 10, 11, 14 y 15 de abril, lo que da una muestra de la escasa importancia que se le atribuye al asunto.

\section{Gráfico 1 \\ Tiempo dedicado al tema en Sky News y Fox News, 9-23 de abril de 2013}

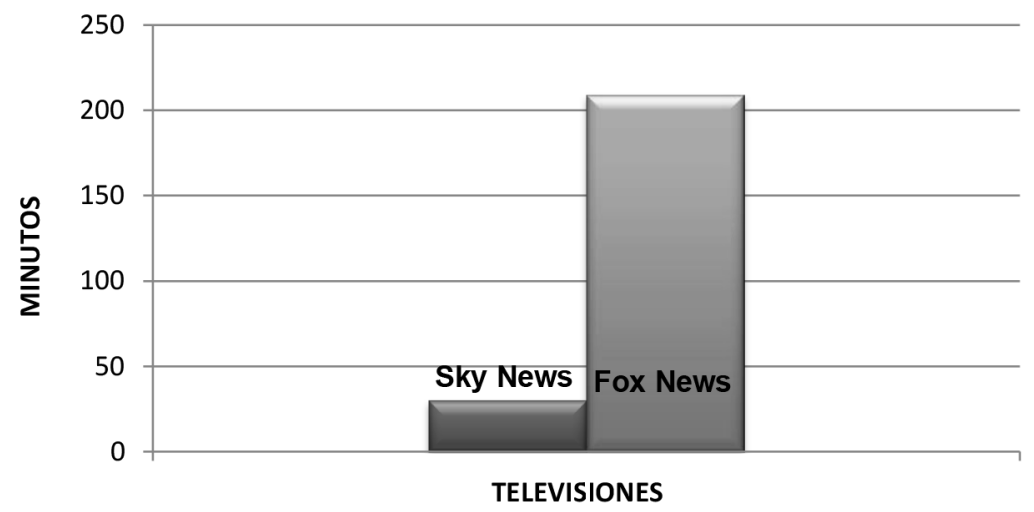

Fuente: Elaboración propia.

\section{Gráfico 2 \\ Distribución temporal de las noticias en Sky News}

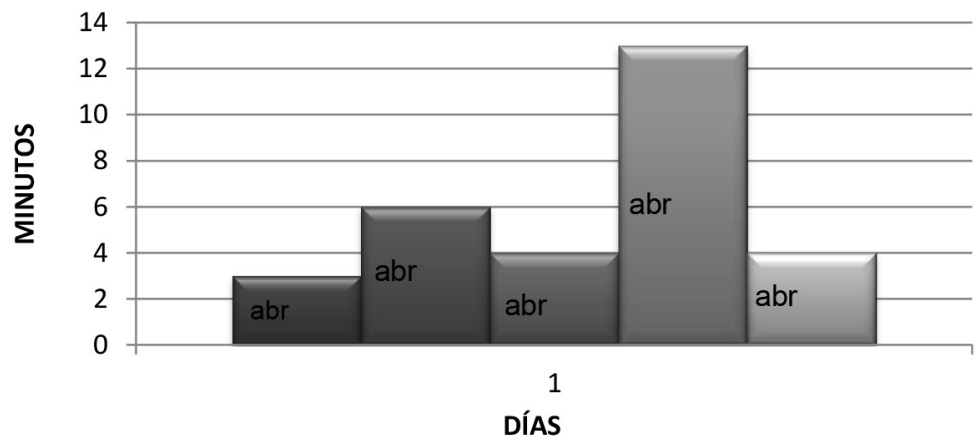

Fuente: Elaboración propia. 
El día que mayor información se difundió sobre el conflicto fue el 14 de abril, con un total de 771 segundos, que supone el 42,29\% de la información para el periodo de estudio, dado que es el momento en el que estalla el escándalo con el documental de la BBC. ${ }^{6}$

El 9 de abril el tiempo total de información sobre el conflicto fue de 152 segundos (8,34\%), el 10 de abril fue de 418 segundos $(22,93 \%)$ y el 11 de abril, 212 segundos (11,63\%). Posteriormente, sólo el 15 de abril contuvo información sobre el conflicto, con 270 segundos, que suponen un $14,81 \%$ del total.

En el caso de Fox News, la distribución del tiempo dedicado al conflicto es la siguiente:

\section{Gráfico 3 \\ Distribución temporal de las noticias en Fox News}

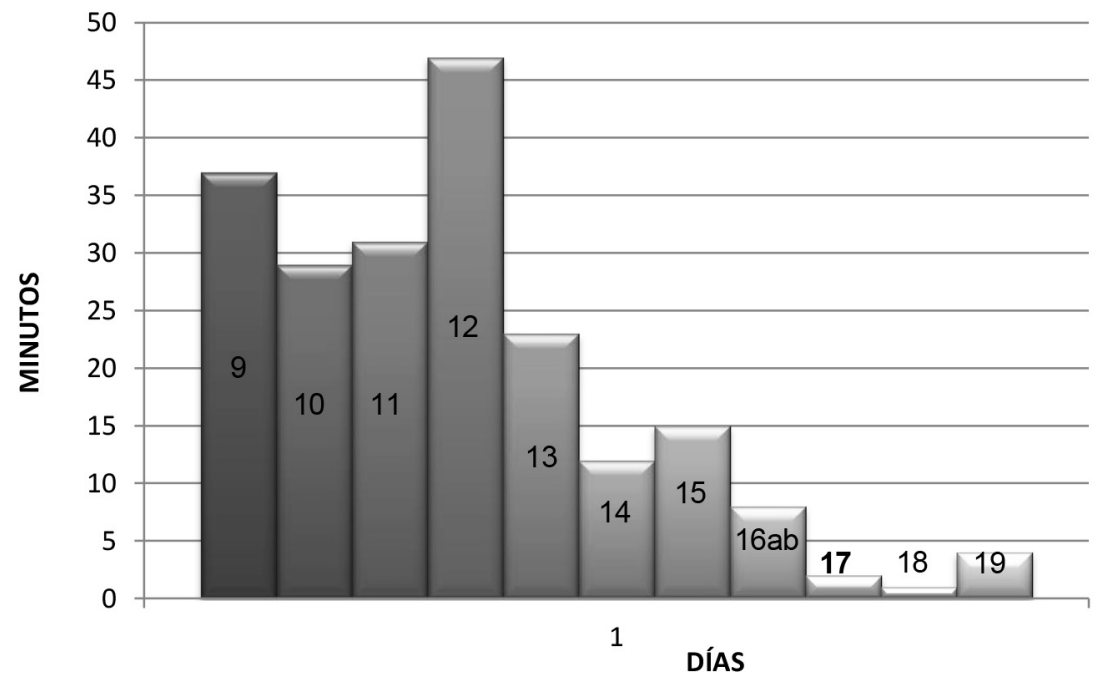

Fuente: Elaboración propia.

6 Se trata de la difusión de un polémico documental en el programa Panorama, donde el presentador John Sweeney entraba en territorio norcoreano junto a otra periodista para grabar imágenes de la situación interna por la que estaba atravesando el país aprovechando un viaje de la Escuela de Estudios Económicos de Londres, sin que ésta fuera informada de tal acción, "poniendo en peligro la integridad de los estudiantes desplazados", según el director de la institución. 
Estos resultados nos hacen suponer que el canal británico Sky News dedica menos espacio a aquellos conflictos de la escena internacional en los que Gran Bretaña no esté directamente inmersa, puesto que hay días en que las noticias sobre la crisis nuclear son omitidas por completo, mientras en Fox News el tema se mantiene de forma regular. No obstante, es importante destacar la disminución de informaciones sobre el conflicto en el canal norteamericano a partir del 15 de abril, provocada por los atentados del maratón de Boston, que acaecieron ese mismo día en la capital del estado de Massachusetts y que se convirtieron en el punto central de los informativos.

Tras realizar el análisis del total de tiempo dedicado al conflicto, procederemos con el análisis de los distintos frames.

\section{Gráfico 4 \\ Frames en Sky News}

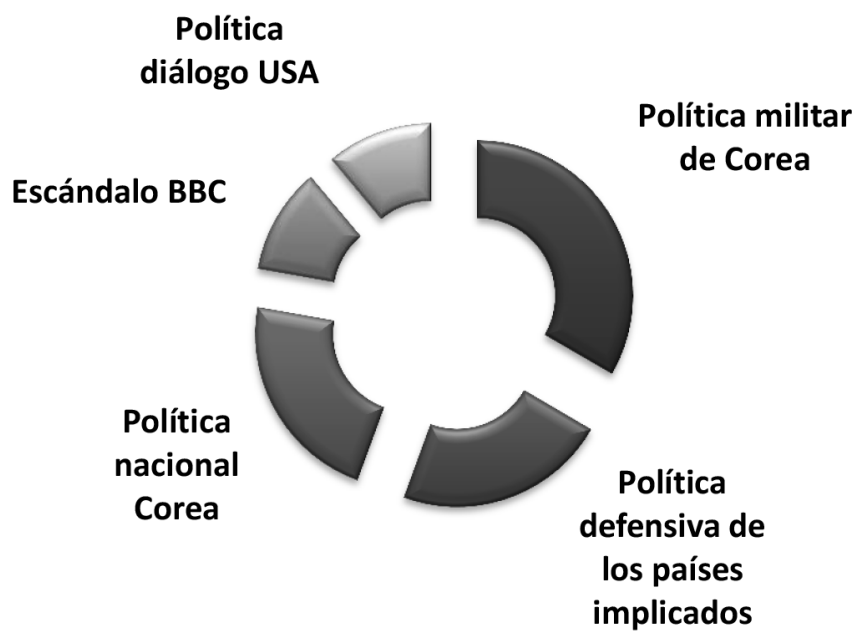

Fuente: Elaboración propia.

Sky News centró su información principalmente en la política militar llevada a cabo por el gobierno de Corea del Norte con continuas imágenes de entrenamientos de soldados norcoreanos. Las noticias de este tipo constituyen más de un tercio de la información total registrada. Las imágenes de soldados entrenando se suelen cruzar con intervenciones de ciuda- 
danos de los países inmersos en el conflicto, donde, por una parte, se critica la actitud del gobierno norcoreano y, por otra, se expresa temor por la posibilidad de un ataque militar. Las imágenes de calles arrasadas por la dictadura militar y el empobrecimiento de la sociedad son el eje central sobre cual se sustenta la información con relación a la política interior del país. Todos estos enfoques vienen acompañados de imágenes de las medidas de seguridad activadas en Japón y Corea del Sur.

El escándalo del documental de la BBC apareció con frecuencia en los informativos de Sky News y fue utilizado como una crítica hacia la cadena pública. En ningún momento se comentó el contenido detallado del trabajo realizado por el programa Panorama, salvo un breve apunte de la temática, recurriendo con frecuencia a la comparación con otros temas polémicos de la BBC, como los reportajes sobre Gadafi o el escándalo sexual de Jimmy Savile. En conclusión, podemos afirmar que Sky News, debido a la poca cantidad de noticias directamente relacionadas con el conflicto, optó por desviar el caso hacia las controversias y escándalos en la BBC con la intención de ejercer una crítica feroz contra su rival en el mercado televisivo británico.

\section{Gráfico 5 \\ Frames en Fox News}

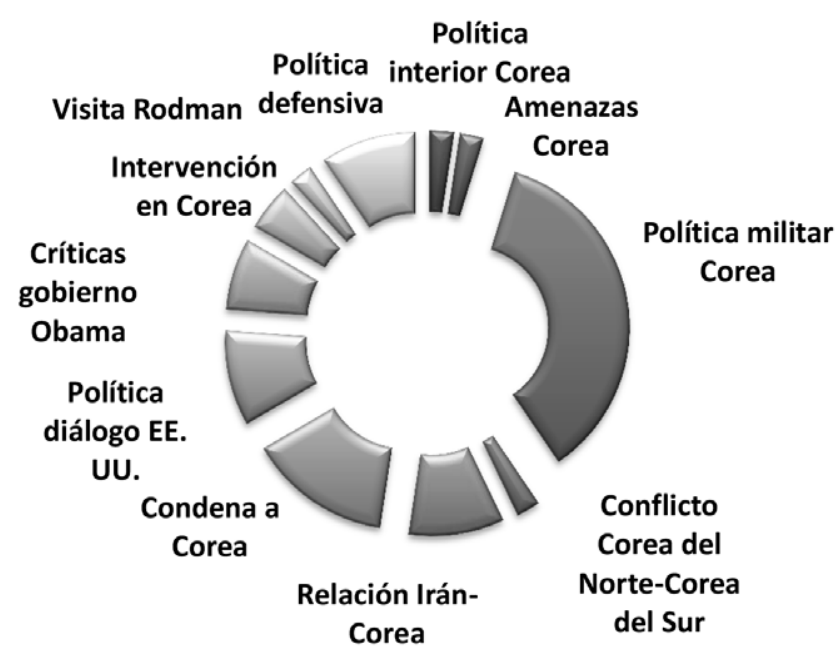

Fuente: Elaboración propia. 
Como podemos observar en el gráfico, la política militar norcoreana se presenta como el punto central de la información en Fox News, abarcando más de un tercio de la información total. Las imágenes de entrenamientos militares y del propio líder norcoreano ocuparon un lugar privilegiado en los noticieros de la cadena norteamericana. Además, Fox News acompañó la mayoría de las noticias con datos sobre el desarrollo de armas nucleares en Corea del Norte y, también, con referencias a anteriores experimentos.

Las condenas al régimen de Kim Jong-un también son habituales, pero en este caso provinieron en su gran mayoría de los expertos invitados al informativo o de antiguos militares y políticos estadounidenses, que ganaron importancia frente a las ruedas de prensa de los políticos. Las declaraciones del antiguo embajador de la ONU, John Bolton, "We don't know if Kim Jong-un manages generals or they manage him", son comentadas en numerosas ocasiones como un argumento para desacreditar la figura de Kim Jong-un, insistiendo que él realmente no controla el país sino que son los generales del ejército quienes toman las decisiones por él.

La política de defensa formó un importante núcleo informativo para la cadena estadounidense, donde nuevamente fueron antiguos militares y expolíticos quienes realizaron las valoraciones de las medidas defensivas con las que cuenta el país. La política de diálogo de la administración Obama también ocupó un lugar destacado en los noticiarios. Precisamente de este tema surge otro elemento habitual en la información de Fox News, que es la crítica hacia el gobierno por no apostar por una respuesta directa ante las provocaciones llevadas a cabo por el régimen de Kim Jong-un. ${ }^{7}, 8$

Un nuevo punto que introdujo la cadena norteamericana fue la relación entre Corea del Norte e Irán. En ciertos casos, algunos de los expertos

\footnotetext{
7 La crisis es utilizada por políticos republicanos como Doug Lamborn para criticar los recortes en defensa llevados a cabo por la administración Obama mientras elogian la política de incremento de la inversión de George W. Bush. David Brock (2005) escribe lo siguiente sobre el tratamiento informativo de la administración Bush en la Fox: “The George W. Bush administration was the first in history to have a TV network rooting for it, a fusion of power that the White House used to its full propaganda potential. On the night of the 2000 election, Fox had been the first to declare Bush the victor. Within a few minutes, all the other networks followed suit" (Brock, 2005).

8 Della Vigna y Kaplan (2006) aportan evidencia de que Fox News influyó en hasta un $8 \%$ de sus espectadores a votar por los republicanos en las elecciones presidenciales de 2000.
} 
aseguraron que el régimen norcoreano podría estar actuando como colaborador del gobierno iraní en su continua lucha contra Estados Unidos. El consultor político Richard Grenell afirmó "Iran is the real threat and John Kerry pays attention to North Korea”. En esta misma línea, uno de los temas preferidos para el periodo de estudio son las siguientes declaraciones de Gordon Chang, columnista en la revista Forbes: "Iran and North Korea, led by China, seek the attack on USA" $y$ "China has to opt for Korea or USA”. En las declaraciones de este abogado podemos observar no sólo una condena a los regímenes coreano e iraní, sino también al gobierno chino por su postura en el conflicto.

Finalmente, debemos añadir los comentarios, ya en un segundo plano, sobre el conflicto entre las dos Coreas, el viaje de Dennis Rodman a Pionyang, las continuas amenazas de Kim Jong-un o la política interior del país asiático. El tono es, en la mayoría de los casos, de crítica a la gestión de la administración Obama. El experto en materia de comunicación Joel Rosenberg dijo en un comentario para Fox News: "Obama has never faced a nuclear crisis", y agregó que por eso no estaba siguiendo una estrategia adecuada en este asunto. El experto puso como ejemplo de buena gestión la intervención de George W. Bush en Irak.

Hablando de discurso, ambos casos estudiados se caracterizan por la presencia de un discurso ético-moral que se torna fácilmente en ético-persuasivo y que acompaña en múltiples ocasiones la información ofrecida. Aquí nos referimos a los extensos comentarios sobre las declaraciones de Obama, la conversación telefónica introducida en uno de los informativos de Sky News con la turista estadounidense en Pionyang Andrea Lee, donde dice del líder coreano Kim Jong-un que "(he) is unpredictable because he is very young", 9 una frase que se va a convertir en la descripción preferida a la hora de hablar de Jong-un.

En el caso de Fox News, podemos dar como ejemplo la intervención del consejero delegado y fundador de la USA Operation, Richard Walden, hablando de malnutrition, humanitarian crisis o danger.

9 Otros adjetivos recurrentes a la hora de describir su personalidad son: instable, crazy y without ablity to direct. 
En la narrativa de Fox News encontramos también una alta dosis de discurso que denominaríamos reputacional y que viene dado por ese sentimiento patriótico que se puede apreciar con frecuencia en todos los informativos de la cadena. La frase del antiguo Secretario General George Galloway, "we have to respond to Korean threats", es repetida en numerosas ocasiones..$^{10}$ Esa frase viene acompañada por análisis de expertos, como en el caso del analista militar de la cadena, el general Jack Keane, quien pone el acento sobre la alta capacidad defensiva de los Estados Unidos.

\section{Conclusiones}

En el caso de Sky News, la información se ofrece desde el prisma de los sucesos a nivel nacional debido al tiempo dedicado a la polémica con el documental del programa Panorama de la BBC. Sería recomendable repetir el estudio para otro periodo de tiempo, para hacer así un seguimiento con el fin de comprobar si se trata de una tendencia o de un caso aislado. Otro elemento por destacar es la opinión como dominante claro del espacio informativo, por encima de la rigurosidad de los datos. En los informativos que conciernen al periodo, podemos destacar la escasa aparición de corresponsales desplazados al lugar de los sucesos, mientras son frecuentes las apariciones de ciudadanos preguntados por su opinión del conflicto, así como las retransmisiones en directo de ruedas de prensa o declaraciones de jefes de gobierno y ministros de los países afectados.

Volviendo a la primera cuestión de investigación, las normas de servicio público sobre la radiodifusión en el Reino Unido y la presencia de la BBC actúan como contrafuerza en el proceso de 'foxificación' de Sky News, debemos decir que las características detectadas demuestran lo contrario -la presencia de alto nivel de sensacionalismo, por una parte, y, por otra, de un discurso militar proveniente de las intervenciones por parte de expertos del ejercito a la hora de interpretar las noticias-. En resumen, la 'foxificación' de la cadena británica parece real aunque hacen falta más estudios sobre sucesos de distinto tipo para llegar a una conclusión definitiva.

10 Otros ejemplos en la misma línea: "We have enough defensive methods" y "We can stop Korean attacks". 
En el caso de Fox News observamos una gran presencia de expertos que introducen una línea ideológica fácilmente distinguible. El tratamiento de la crisis nuclear de Corea del Norte consiste en una apropiación continua del conflicto a través de constantes críticas a las políticas militares llevadas a cabo por Corea y la exaltación patriótica de los Estados Unidos poniendo el acento sobre el sistema defensivo, todo ello rodeado de una crítica feroz al gobierno de Barack Obama por no promover una intervención en el país asiático en lugar de apostar por una política de diálogo. ${ }^{11}$ Los resultados obtenidos y los ejemplos señalados dejan claro que la segunda cuestión previamente formulada queda confirmada: sigue existiendo una dependencia significativa en Fox News de los expertos militares para interpretar temas relacionados con las relaciones internacionales de los Estados Unidos.

William Raspberry (2005) afirma que el partidismo de derecha que caracteriza a las noticias de Fox News está teniendo consecuencias muy negativas para el sistema mediático estadounidense. La popularidad del enfoque Fox está golpeando fuertemente a su competencia directa ( $\mathrm{CNN}$, CNBC, Msnbc, etc.) porque conduce a otras emisoras de cable a imitar, lo que a su vez degrada la calidad de las noticias. La segunda tendencia, mucho más peligrosa, consiste en que el efecto amenaza con destruir la confianza pública en las noticias. ${ }^{12}$

El periodo que hemos analizado nos permite detectar una característica que merece nuestra atención y que debe convertirse en punto de partida para futuras investigaciones en el campo. Se trata del 'abandono' de una

11 Brock y Rabin-Havt señalaron en 2012: "Lo más habitual en las noticias de Fox eran partidarios políticos e ideológicos raramente vistos en el resto de organizaciones profesionales de noticias. David Asman, presentador durante el día, había salido de la página editorial de The Wall Street Journal y del Instituo Manhattan. Brit, de ABC News, presentador de los informativos de la noche, pluriempleado como escritor freelance para American Spectator, periódico de extrema derecha, y para el neoconservador Weekly Standard. Tony Snow, presentador eventual y hasta hace poco presentador del programa matutino del domingo de Fox, era el editor de la página editorial del Washington Times y escritor de los discursos de George Bush durante su etapa en la Casa Blanca” (traducción del autor).

12 Según Aldro Vico (2013, p. 77), "La crisis del sistema político, la crisis de confianza en el sistema representativo de los políticos profesionales, es otra catástrofe paralela y diríamos que hermana de la crisis del periodismo. Hemos visto que Lippman, en los años 20, ya diagnosticaba que ambos eran causa y efecto de un mismo proceso. Los mismos procesos de profesionalización salvaje han llevado a ambos oficios a perder su horizonte ético y a vaciarse de valor social. Se trata de dos de las profesiones menos valoradas en las encuestas sociales de 2010. De nuevo se nota la desaparición del valor simbólico de las instancias mediadoras, en una sociedad en la que ya no son necesarias, y en la que además, se han vuelto indeseables, por su corrupción y por su ejercicio de falsa conciencia”. 
noticia dedicada a un asunto de gran transcendencia calificado como crisis nuclear por otro suceso de otro ámbito distinto al anterior. Todo esto se traduce en la falta de noticias del Corea del Norte a partir del día 15 de abril, provocada por los atentados del maratón de Boston. Este desplazamiento total del punto de atención de un acontecimiento hacia otro despierta la duda de si no estamos otra vez ante un espectáculo hiperreal como los muchos que hemos presenciado a lo largo de los años en distintos canales y espacios informativos en los EE. UU., pero también en el resto del mundo.

A pesar de las limitaciones que presenta un estudio de este tipo y de las dificultades que supone la comparación de narrativas, debemos remitirnos a las directrices propuestas por Entman, quien considera que el acto de comparar puede ser de gran ayuda a la hora de detectar los frames (1991, p. 6). Además, el framing siempre ha defendido que los análisis bien enfocados y claramente limitados en el tiempo pueden servir como mecanismos muy útiles para la descripción de tendencias que, por su parte, deben ser probadas una y otra vez, lo que convierte el enfoque en un cometido altamente colaborativo.

\section{Bibliografía}

Aladro Vico, E. (2013). “Las teorías profesionales ylas 5 crisis del periodismo”. En: Cuadernos de Información y Comunicación, 18, pp. 69-81.

Bardin, L. (2002). Análisis de contenido. Madrid: Ediciones Akal.

Bateson, G. (1993). Una unidad sagrada. Pasos ulteriores hacia una ecología de la mente. Madrid: Gedisa.

Berelson, B. (1971). Content analysis in communication research. Nueva York: II University Press.

Blesa Aledo, P. (2006). "Medios de comunicación y democracia: ¿El poder de los medios o los medios al poder?”. En: Sphera Publica, 6, pp. 87-105. 
Brock, D. y Rabin-Havt, A. (2012). The Fox Effect: How Roger Ailes Turned a Network into a Propaganda Machine. Washington: Mediamatters for America Ed.

Brown, M. (2011). "ITV considered replacing half of evening news with gameshow”. En: The Guardian, 18 de enero de 2013. Disponible en: http://www.guardian.co.uk/media/2011/jan/18/itv-earlyevening-news [fecha de consulta: 30 de abril de 2014].

Borah, P. (2011). "Conceptual issues in framing theory: A systematic examination of a decade's literature". En: Journal of Communication, 61, pp. 246-263. Disponible en: http://porismitaborah.com/Borah,2011_JOC.pdf [fecha de consulta: 30 de abril de 2014].

Bustelo, P. (2008). “Corea del Norte: ¿hacia la desnuclearización, por fin?”. En: Anuario Asia Pacífico, 2013, pp.147-155.

Crusafon, C. (2009). "Las nuevas plataformas digitales: análisis de las estrategias desarrolladas por los informativos de las network estadounidenses ( $\mathrm{ABC}, \mathrm{CBS}$ y NBC) y de las cadenas temáticas (CNN, FOX NEWS y MSNBC)". Comunicaciones del II Congreso Internacional de Teoría y Técnica de los Medios Audiovisuales. Universitat Jaume I, Castellón.

Cushion, S. y Lewis, J. (2009). “Towards a 'Foxification’ of 24-hour news channels in Britain?: An analysis of market-driven and publicly funded news coverage”. En: Journalism, 10 (2), pp. 131-153.

Cushion, S. (2011). Television Journalism. Londres: SAGE.

Cushion, S., Lewis, J.y Neil Ramsay, G. (2012). “The impact of interventionist regulation in reshaping news agendas: A comparative analysis of public and commercially funded television journalism". En: Journalism, 13 (7), pp. 831-849.

Della Vinga, S. y Ethan, K. (2006). “The Fox News Effect: Media Bias and Voting”. 
Disponible en: http://elsa.berkeley.edu/ sdellavi/wp/foxvote06-03-30. pdf\#search=\%22fox\%20news\%20studies\%22 [fecha de consulta: 30 de abril de 2014].

Entman, R. M. (1991). "Framing U.S. coverage of international news: Contrasts in narratives of the KAL and Iran Air incidents". En: Journal of Communication, 41, pp. 6-27.

Entman, R. (1993). "Framing: Toward Clarification of a Fractured Paradigm”. En: Journal of Communication, 43 (4), pp. 51-58.

Fairclough, I. y Fairclough, N. (2012). Political Discourse Analysis: A method for advanced students. Nueva York: Routledge.

Fairclough, N. (2002). Discourse and Social Chang. Cambridge: Polity Press.

Fairclough, N. (1995). Media Discourse. Londres: Edward Arnold.

Freedman, D. (2008). The Politics of Media Policy. Cambridge: Polity Press.

Gibson, O. (2008). “BBC journalists accused of London bias”. En: The Guardian, 12 de junio de 2008. Disponible en: http://www.guardian.co.uk/media/2008/jun/12/bbc.tvnews [fecha de consulta: 30 de abril de 2014].

Goffman, E. (2006). Frame analysis: los marcos de la experiencia. Madrid: CIS.

Lasswell, H., Leites, N, Fadner, R., Goldsen, J., Grey, A., Janis. I., Kaplan, A., Mintz, A., De Sola Pool, I., Yakobson, S. y Kaplan, D. (1965). Language of Politics. Studies in Quantitative Semantics. Cambridge, Massachusetts: The M.I.T. Press.

Matthes, J. y Kohring, M. (2008). “The content analysis of media frames: toward improving reliability and validity”. En: Journal of Communication, 58, pp. 258-279. 
McChesney, R. (2000). Rich Media, Poor Democracy. Communication Politics in Dubious Times. Urbana: University of Illinois Press.

McChesney, R. (2008). The Political Economy of Media: Enduring Issues, Emerging Dilemmas. Nueva York: Monthly Review Press.

Raspberry, W. (2005). “Fox's Sandstorm”. En: The Washington Post, 18 de abril de 2005. Disponible en: http:/ /www.washingtonpost.com/ wpdyn/content/article/2005/04/18/AR2005041800425.html [fecha de consulta: 30 de abril de 2014].

Reese, S. D. (2001). "Framing Public Life: A Bridging Model for Media Research”. En: Reese, S. D., Gandy, O. H. y Grant, A. E. (eds.). Framing Public Life: Perspectives on Media and our Understanding of the Social World (pp. 83-94). Mahwah, NJ: Lawrence Erlbaum Associates.

Semova, D. J. (2010). "Los primeros cien días del nuevo gobierno de Bulgaria según la prensa: un análisis de contenido”. En: Cuadernos de Información y Comunicación, 15, pp. 251-261. Disponible en: http://revistas.ucm.es/index.php/CIYC/article/viewFile/ CIYC1010110251A/7207 [fecha de consulta: 30 de abril de 2014].

Semova, D. (2012). Entender la radiotelevisión pública. Madrid: Liberlibro.

Sirota, D. J. (2004). “The Fox of War”. En: www.salon.com, 30 de marzo de 2004. Disponible en: http://archive.salon.com/news/feature/2004/03/30/fox_news/index.html [fecha de consulta: 30 de abril de 2014].

Tankard, J. (2001). “The Empirical Approach to the Study of Media Framing”. En: Reese, S. D., Gandy, O. H. y Grant, A. E. (eds.). Framing Public Life: Perspectives on Media and our Understanding of the Social World (pp.95-106). Mahwah, NJ: Lawrence Erlbaum Associates. 
Tuchman, G. (1978). Making News: A Study in the Construction of Reality. Nueva York: Free Press.

Wodak, R. (2005). New Agenda in (Critical) Discourse Análisis: Theory, Methodology and Interdisciplinarity. Amsterdam/Philadelphia: John Benjamins Publishing Company. 